\title{
Voltage Sensing Technique for Renewable Energy Sources Self-Intervention
}

\author{
Ranjit Singh Sarban Singh, Maysam Abbod, Wong Yan Chiew
}

\begin{abstract}
Solar photovoltaic and wind energy resources are gaining more popularity as an integrated or complementary power system. Integrating or complementing either solar photovoltaic or wind energy would be an ideal to reduce the intermittency when self-intervention from either one of the input resources is performed. The self-intervention plays a vital role in renewable energy resources hybridization, hence this paper proposes to model and simulate an adaptive voltage-divider sensing method to perform the self-intervention technique for renewable energy resources hybridization using the Stateflow/Simulink MATLAB software. The proposed adaptive voltage-divider sensing method performs the voltage sensing and measurement for input voltages from either one of the renewable energy resources adopted. This voltage sensing and measurement is an important factor to demonstrate the self-intervention in the designed and developed Stateflow/Simulink MATLAB Controller. The proposed adaptive voltage-divider sensing method and self-intervention technique for renewable energy resources hybridization is analyzed along with the voltage sensing and measurement at the inputs. The self-intervention state modes for the inputs from the renewable energy resources hybridization are given by the simulation results in this study.
\end{abstract}

Keywords : Complementary power system, Hybrid RESs, MATLAB System, Self-Intervention, Stateflow/Simulink.

\section{INTRODUCTION}

$\mathrm{F}_{\text {ossil fuels such as coal, natural gas and petroleum are }}$ one of the world's most important sources to produce electricity. In 2011, $68 \%$ of the world electricity is generated using the fossil fuels, $19 \%$ using the nuclear energy and $13 \%$ using renewable resources and other sources [1]. It is estimated that by $2040,66 \%$ of world electricity will be generated using the fossil fuels, $17 \%$ using the nuclear energy and $17 \%$ using the renewable resources and other sources [1]. Looking at figures, even by the year of 2040 world electricity generation will be still dependent on the fossil fuels. Having said that, some prospects are seen generating electricity using the renewable resources by the year of 2040. Even though this is seen as a positive progressive improvement but relatively the improvement is significantly very low compared to the year 2011. This positive progression is based on some of the previous and current development in the renewable energy technology system for electricity generation such as like in [2], [3], [4]. Ever since, electricity power generation system based on renewable energy resources have been developed and offer its application in various off-grid and

Revised Manuscript Received on October 25, 2019.

Ranjit Singh Sarban Singh, Universiti Teknikal Malaysia Melaka, Melaka, Malaysia

Maysam Abbod, Universiti Teknikal Malaysia Melaka, Melaka, Malaysia

Wong Yan Chiew, Universiti Teknikal Malaysia Melaka, Melaka, Malaysia grid-connected networks. As the technology development got matured through extensive research, the integration or application of the renewable resources as electricity generator has and is becoming more essential. This can be noticed when the world is getting more serious on the global warming and carbon dioxide issues. Research in also showed that using the fossil fuels to generate electricity will not only cause harm to the world, indeed will also unable to replenish the used fossil fuel. Hence, the electricity energy production from the renewable resources are being considered as a viable alternative to replace the depleting fossil fuels. Among the renewable resources, solar photovoltaic energy and wind energy are the most promising renewable energy resources to capture the available energy in the sun and wind to convert into electrical energy as power. During the early stage of solar photovoltaic and wind source energy system research and development, single renewable source types of system were promoted around the world [1]. These type of systems are good for short period of time operation, whilst unable to sustain for continuous operation due to their uncertain climate change [2]. Therefore, hybrid system was introduced to overcome the solar photovoltaic and wind system operation during the uncertain climate change. In this context, hybrid system in its general view combines several available renewable resources to generate electricity [3]. It is also the best manner to cater to the connected loads and provide sufficient electricity to the ever growing demand [4]. Having said that, the renewable energy resources hybridization (HRES) system still need to be exploit to ensure their cost-effective and its reliability in delivering continuous electricity power. The introduction of complementary power system (CPS) is one of the solutions to compensate between the solar photovoltaic and wind energy electricity generation [5]. N. Chen et. al. [5], the self-intervention technique between supply and load for HRES is introduced to increase the electricity generation in certain percentage for all around the year. Other than that, the self-intervention technique also is said will be able to achieve an appropriate loading and unloading corresponding process among the solar photovoltaic and wind energy.

Adopting the idea of self-intervention, this paper introduces the voltage based self-intervention technique for solar photovoltaic and wind renewable energy resources for the Hybrid Solar Photovoltaic (PV) - Wind Energy System (HSPV-WES). The voltage based self-intervention technique for the HSPV-WES is modelled and simulated using the Simulink/MATLAB software platform to address the loading and unloading of the solar photovoltaic and wind energy based on the input supply voltage for each renewable energy resources. However, to do so, the input voltage is categorized into four categories and each input voltage category is discussed of its usability and

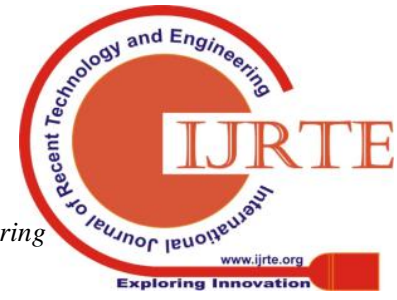


importance. The highlights of the four input voltage categories are then presented with the simulation results. Finally, the voltage-based self-intervention clearly describes combining solar photovoltaic and wind energy and performing the self-intervention could improve the HRES uncertain climax for continuous electricity generation.

\section{LITERATURE REVIEW}

Renewable energy resources-based power system makes a substantial contribution to increase the demand of the electricity. The renewable energy system and technology have gone through various evolutions in terms of design and development to improve the energy and electricity production. However, because each of the renewable energy have unpredictable and random behaviours [6], the hybridization or complementary power system is much favourable to have a continuous electricity generation with a continuous input resources from either the solar or wind energy. Due to their suitability as hybridization or complementary power system, the power systems are always designed and developed using the hybridization configuration [7]. The major aspect of the hybrid system configuration is to have a reliable and stable power generation system which varies under the different atmospherics conditions. Considering reliable and stable power generation system [8], the input from the energy sources needs to be consistent and uninterrupted. Hence, it is essential to have a proper control strategy, operation and management between the connected renewable energy resources, such as solar photovoltaic system and wind energy system. There are several works conducted previously comprising photovoltaic and wind energy. Kuo et al [9] proposed a synthesized system which is used to control various operation mode of the hybrid renewable energy system especially controlling the switching frequency between the continuous current mode (CCM) and discontinuous current mode (DCM) to improve the system efficiency and stability. Almi et al [10] proposed electric power control and interconnection between the wind energy and the photovoltaic for maximum energy extraction from either sources during the varying conditions of the wind speed and solar irradiance. In [11], the research proposed a simulation and modelling to eliminate the instability between the wind energy and solar photovoltaic during the weather varying condition. They discussed about the floating average method and corresponding control strategy to perform smoothness between the battery-supercapacitor charging-discharging processes. The floating average method and corresponding strategy managed to reduce the stabilize power fluctuation from both sources while keeping the energy storages at safe stage.

Wen et al in [12] also proposed the control operation mode based on the characteristics of solar photovoltaic, the maximum power point tracking (MPPT) is adopted with the perturbation and observation (PO) method and constant voltage control (CVC) method. This is to ensure the efficient and stable operation of the DC microgrid operation. The MPPT is only activated when the input of the solar irradiance is not enough to be supplied to the connected load. The MPPT will only operate along with the boost converter when the input supply is not enough to supply directly to the load. This is known as constant voltage control (CVC) mode. During the CVC mode, the DC line input supply will be increased and supplied to the load. Natsheh et al [13] uses the artificial neural network (ANN) and fuzzy logic (FL) controllers to manage the power flow between the stand-alone hybrid power system and energy storage system to satisfy the load demand. The ANN is employed to achieve the optimum output from the MPPT while FL is employed to disseminate the harvested energy between the power systems and control the charging and discharging to optimize the system performances.

Reviewing the work in [9], [10], [11], [12], [13], the research conducted propose inverters, MPPT, CVC, PO, ANN and FL methods to enhance the efficiency of the system in terms of the complementary system, improving the battery energy storage (BES) charging and discharging capability, accommodating the load demand based on the input from the power system and BES. In [14], the proposed system is built to optimize the algorithm that associates the hydrological system with solar irradiation data. The solar irradiation data is used by the algorithm to examine the possible PV panel's alteration that assist to increase the complementary of the solar energy output. Similar approach was used in [15], the research proposed to use different climate related information to increase the system's complementarity which is based on multiple resources. The obtained results validate that the benefits of having sharing resources for a complementary system. Thereafter, the developed HRES mainly discusses on the overall system delivery even though complementary power system has been integrated as an overall HRES. Even though complementary system has been introduced to overcome the geographical and seasonal effects on the output especially the PV-wind complementary power system [16].

Despite the development of the complementary power system to overcome geographical and seasonal drawbacks, yet a proper adaptation of control and switching between two input renewable energy resources is still required, necessary and can be explored. This research proposes modelling and simulation of Voltage Based Self-Intervention Technique for Hybrid Photovoltaic (PV) - Wind Energy System (HPVWES). Taking into consideration about complementary power system characteristics, the voltage measurement method is used to develop the control and switching controller between the solar photovoltaic and wind energy renewable energy resources using the Simulink/MATLAB modelling and simulation software.

This paper is organized as follow. In the first section, the voltage based self-intervention technique is explained. It is then followed with the control and switching controller design and development using Simulink/MATLAB modelling and simulation software. Lastly, the voltage based self-intervention technique and control and switching results are presented and discussed. And finally, the objective of this paper is concluded.

\section{VOLTAGE SENSING TECHNIQUE FOR RESS SELF-INTERVENTION}

The proposed Voltage Based Sensing Self-Intervention technique comprises of adaptive voltage-divider, a voltage sensor, a physical signal to Simulink signal converter, analogue to digital (ADC) and Stateflow designed controller. Figure 1 shows the proposed Voltage Based Self-Intervention technique for solar photovoltaic and wind hybrid renewable energy resources. In 
this section each of the component's operation, functionality and results validity will be discussed.

\section{A. Adaptive Voltage-Divider Sensing}

In order to overcome the geographical and seasonal effects on the HSPVWES power output, it is important to measure the output voltage of each renewable energy resources for continuous monitoring. The output voltage of each renewable energy resources is sensed and measured using the adaptive voltage-divider concept as shown in Fig. 2. The adaptive voltage-dividers are adapted, each to measure the output voltage from the solar photovoltaic and wind energy systems. As illustrated in Fig. 1, the adaptive voltage-dividers are connected at the output of the charge controller system. The adaptive voltage-divider ensures the minimum and maximum amount of energy allowed for harvesting and storing purposes. The voltage sensor is integrated in parallel to the Resistor $R_{1}$. The sensed and measured voltage at the voltage sensor is directly proportional to the voltage drop across the Resistor $R_{1}$. Hence, if the input voltages from either of the solar photovoltaic or wind energy system become less, the sensed and measured voltage at the voltage sensor also become less. The sensed and measured voltage at the voltage sensor is the output voltage to the Stateflow/Simulink MATLAB controller. Hence, in the following section the adaptive voltage-divider sensing operation is explained.

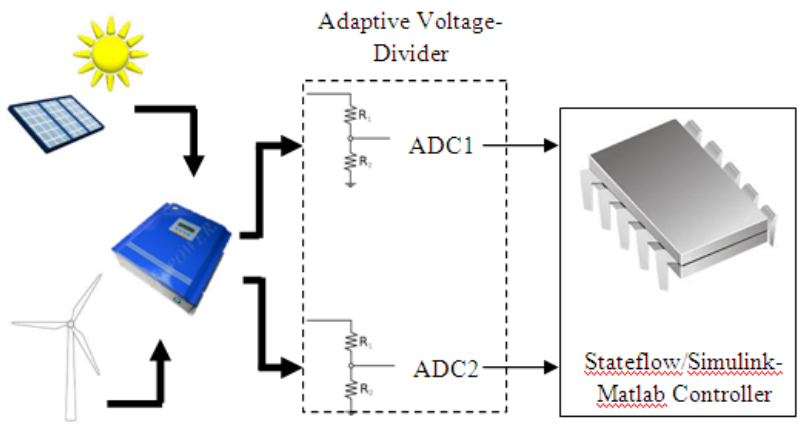

Fig. 1. Proposed voltage-based self - intervention technique for renewable energy resources.

Considering the voltage input $\left(V_{\text {input }}\right)$ required is 14 Volts, thus resistor $1\left(R_{1}\right)$ value need to be maximum and resistor 2 $\left(R_{2}\right)$ value need to be as minimum as possible. Both resistors' values have to be calculated specifically for this application.

Let's say,

$$
\begin{aligned}
& R_{1}=11.14 \mathrm{k} \Omega \\
& R_{2}=1.86 \mathrm{k} \Omega \\
& \text { Voltage Output, }\left(V_{\text {output }}\right)=12 \text { Volts }
\end{aligned}
$$

Voltage Divider:

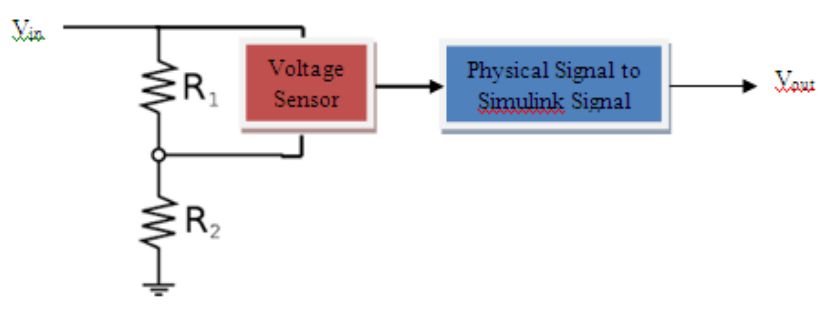

Fig. 2. Adaptive voltage-divider sensing.

As it has been mentioned, the adaptive voltage divider-sensing voltage output is always proportional to the input voltage, $\left(V_{\text {input }}\right)$. Hence, if the $V_{\text {input }}=10.5$ Volts, then $V_{\text {output }}=9$ Volts. Fig. 3 shows the $V_{\text {output }}$ and $V_{\text {input }}$ relationship when both $R_{1}$ and $R_{2}$ values are constant.

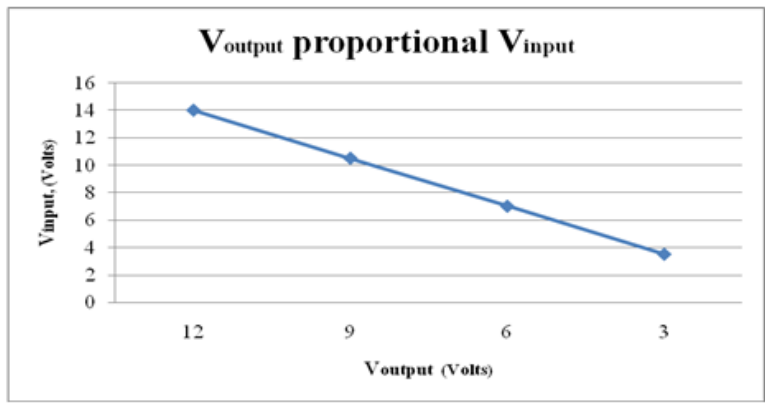

Fig. 3. Voltage output proportional voltage input.

The $V_{\text {out }}$ value from adaptive voltage-divider sensing in the Fig. 2 is used to convert into digital value. This voltage value is used to perform the self-intervention in the Stateflow/Simulink MATLAB Controller. The analogue to digital conversion process is discussed in the results and discussion section.

\section{B. Stateflow/Simulink MATLAB Controller Design}

Fig. 4 shows the proposed Stateflow/Simulink Matlab controller design of the self-intervention technique for HPVWES using the adaptive voltage-divider sensing method. Fig. 4 describes the fundamental development characteristics of the self-intervention controller. The development of the self-intervention controller for HSPVWES is constituted with two controllers, namely (a) Primary Controller and (b) Secondary Controller. Both controllers operate base on sensed and measured voltage using the adaptive voltage-divider sensing method. Tables I and II explain the pre-set conditions involved in designing and developing the self-intervention controller for individual solar photovoltaic and wind energy resources.

The primary controller is designed and developed to perform the self-intervention of HSPVWES base on the sensed and measured voltage by the adaptive voltage-divider sensing method. There are four conditions involved, mainly two for the solar photovoltaic between $6-12$ Volts and two for the wind energy between $6-12$ Volts.

The secondary controller is designed and developed to perform the self-intervention of the HPVWES only when the sensed and measured voltage by the adaptive voltage-divider-sensing method is between $3-6$ Volts. There are two conditions involved, mainly one for the solar photovoltaic between $3-6$ Volts and one for wind energy between $3-6$ Volts. 
Table I- Primary controller conditions for hybrid renewable energy resources

\begin{tabular}{|c|c|c|}
\hline Resources & Conditions & Output Voltage $\left(V_{\text {out }}\right)$ \\
\hline $\begin{array}{c}\text { Solar Photovoltaic } \\
\text { (SP) }\end{array}$ & $\begin{array}{c}9 \leq \mathrm{SP} \leq 12, \mathrm{WE}< \\
9\end{array}$ & $\begin{aligned} \mathrm{SP}= & 9-12 \text { Volts, WE } \\
& =8.9 \text { Volts }\end{aligned}$ \\
\hline Wind Energy (WE) & $\begin{array}{c}9 \leq \mathrm{WE} \leq 12, \mathrm{SP}< \\
9\end{array}$ & $\begin{aligned} \mathrm{WE} & =9-12 \text { Volts, } \mathrm{SP} \\
& =8 \text { Volts }\end{aligned}$ \\
\hline $\begin{array}{c}\text { Solar Photovoltaic } \\
\text { (SP) }\end{array}$ & $\begin{array}{c}6 \leq \mathrm{SP} \leq 9, \mathrm{WE}< \\
6\end{array}$ & $\begin{array}{c}\mathrm{SP}=6-9 \text { Volts, } \mathrm{WE}= \\
5 \text { Volts }\end{array}$ \\
\hline $\begin{array}{l}\text { Wind Energy } \\
\text { (WE) }\end{array}$ & $\begin{array}{l}6 \leq \mathrm{WE} \leq 9 \\
\mathrm{SP}<6\end{array}$ & $\begin{array}{l}\text { WE }=6-9 \text { Volts, } \\
\mathrm{SP}=5 \text { Volts }\end{array}$ \\
\hline
\end{tabular}

Table II-Secondary controller conditions for hybrid renewable energy resources

\begin{tabular}{|c|c|c|}
\hline Resources & Conditions & Output Voltage $\left(V_{\text {out }}\right)$ \\
\hline $\begin{array}{c}\text { Solar Photovoltaic } \\
\text { (SP) }\end{array}$ & $\begin{array}{c}3 \leq \mathrm{SP}<6, \mathrm{WE}= \\
2\end{array}$ & $\begin{array}{c}\mathrm{SP}=3-6 \text { Volts, WE } \\
=2 \text { Volts }\end{array}$ \\
\hline Wind Energy (WE) & $\begin{array}{c}3 \leq \mathrm{WE}<6, \mathrm{SP}= \\
2\end{array}$ & $\begin{array}{c}\mathrm{WE}=3-6 \text { Volts, SP } \\
=2 \text { Volts }\end{array}$ \\
\hline
\end{tabular}

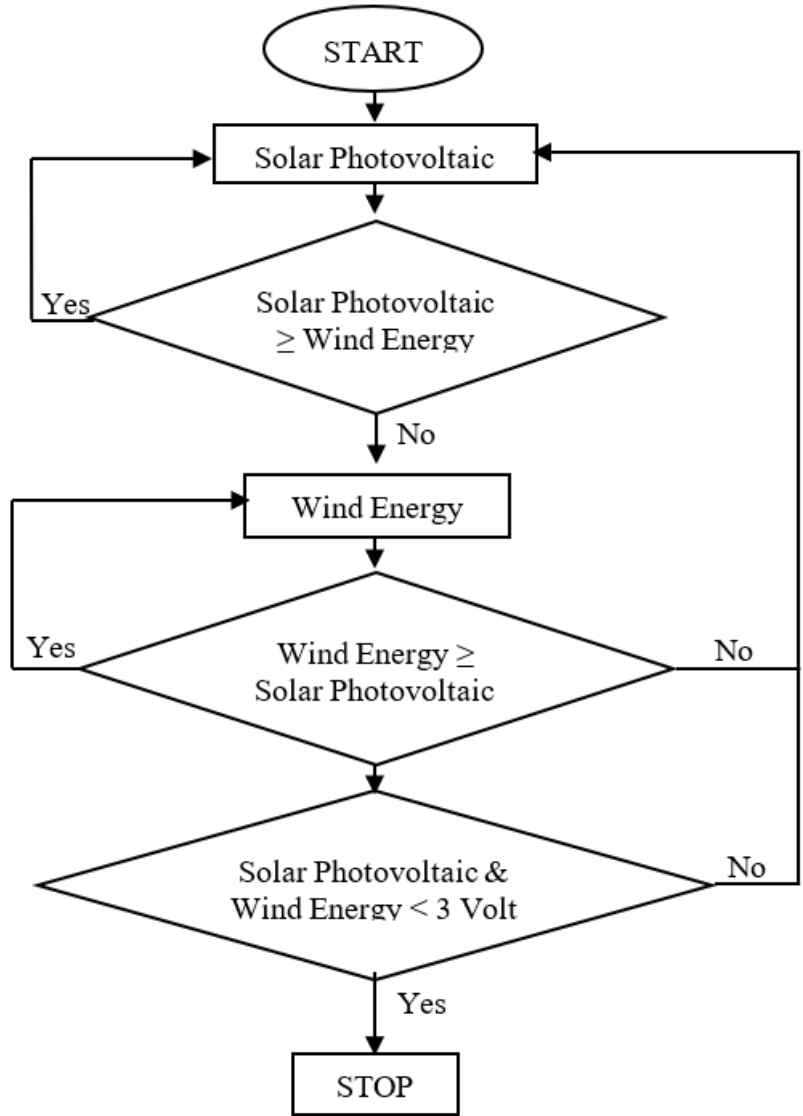

Fig. 4. Stateflow/Simulink MATLAB controller operation flowchart.

The controller sense and measure the voltage changes to simultaneously perform the self-intervention between the hybridized renewable energy resources. The results and discussions of self-intervention of the primary and secondary controller is presented in the next section.

\section{RESULTS, ANALYSIS AND DISCUSSION}

In this section, the adaptive voltage-divider sensing which explains the analog to digital conversion in section 2.1 results are presented in section 3.1. The presented results explain some chosen condition based on Tables I and II.

\section{A. Adaptive Voltage-Divider Sensing - Analog to Digital Conversion}

This section discusses about the analogue input voltage from either one of the hybridized renewable energy resources conversion into digital values.

For instance,

Condition 1: $9 \leq \mathrm{SP} \leq 12, \mathrm{WE}<9$ (Table 1)

The solar photovoltaic is producing voltage between $9-12$ Volts, while the wind energy is less than 9 Volts. The adaptive voltage-divider sensing sense and measure the voltage across $R_{1}$ (Fig. 2), then the sensed and measured $V_{\text {out }}$ voltage (Fig. 2) value is converted into digital value for the Stateflow/Simulink MATLAB controller to perform the self-intervention between the hybridized renewable energy resources.

Fig. 5 shows the y-axis represents the minimum $V_{\text {out }}$ to maximum $V_{\text {out }}$ produced by the hybrid renewable energy resources (solar photovoltaic and wind energy) and $\mathrm{x}$-axis represents the minimum to maximum digital voltage after the analogue to digital conversion process. The digital voltage value is then used by the Stateflow/Simulink MATLAB controller to perform the self-intervention between the hybrid renewable energy resources. Next section discusses on the self-intervention renewable energy resources hybridization based on the digital voltage, whilst also describes the designed Stateflow/Simulink MATLAB controller.

Analogue to Digital Conversion
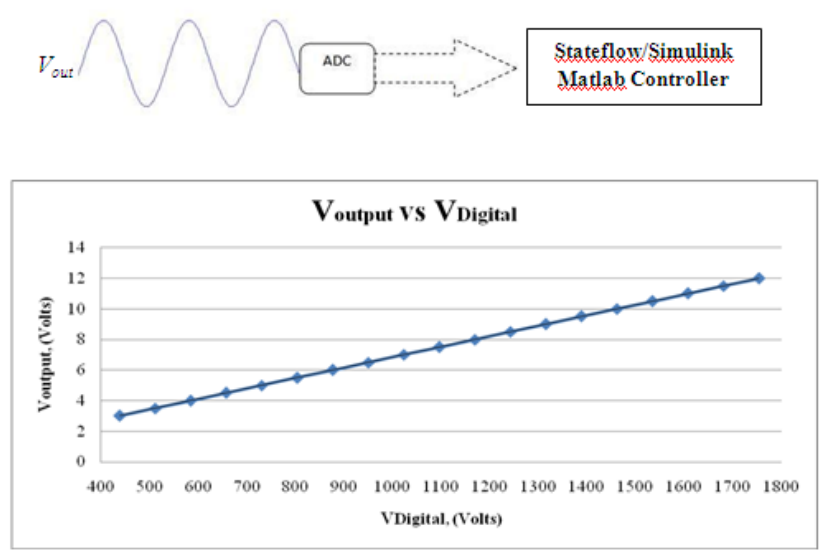

Fig. 5. Voltage output vs voltage digital after analogue to digital conversion.

\section{B. Stateflow/Simulink MATLAB Controller}

The Stateflow chart in the Simulink/MATLAB software is used to design and develop the controller to simulate and perform the self-intervention of renewable energy resources hybridization. In this section, two conditions from Table I and one condition from Table II is discussed and explained.

\section{i. Condition 2: $9 \leq \mathrm{WE} \leq 12, \mathrm{SP}<9$}

Fig. 6 is referring to condition 2 given in the Table I, where the wind energy is producing voltage between $9-12$ Volts, while solar photovoltaic 
voltage is less than 9 Volts. During this condition, wind energy voltage is always higher compared to the solar PV voltage and the controller indicates the signal W12V as HIGH (1). The W12V signal indicates that the wind energy is producing output voltage between $9-12$ Volts.

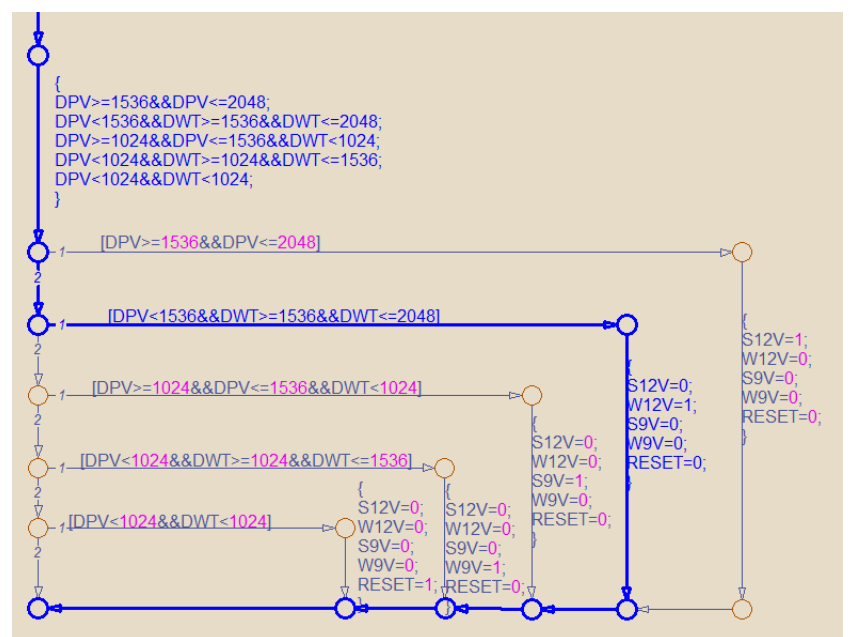

Fig. 6. Wind energy voltage is between 9 - 12 volts, solar photovoltaic voltage less than 9 volts.

Referring to Fig. 7 at time $=5.05$ seconds, solar photovoltaic voltage decreased to 8.925 Volts, which is equivalent to digital voltage of 1305 and wind energy voltage increased to 12 Volts. During this time, referring to Fig. 6, Stateflow/Simulink MATLAB controller performs self-intervention from the solar photovoltaic to wind energy source.

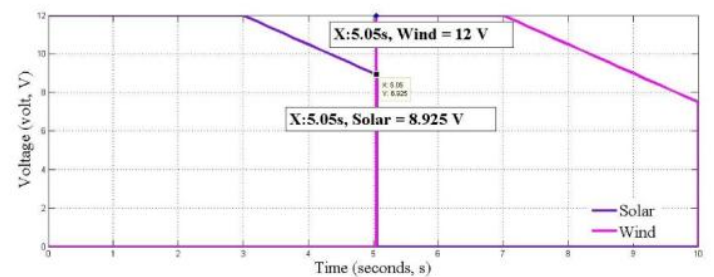

Fig. 7. Self-Intervention solar photovoltaic to wind energy based on condition 2.

ii. Condition $3: 6 \leq \mathrm{SP} \leq 9$, $\mathrm{WE}<6$

Fig. 8 is referring to condition 3 given in the Table I, where solar photovoltaic is producing voltage between $6-9$ Volts, while wind energy output voltage is less than 6 Volts. During this condition, solar photovoltaic voltage is always higher compare to the wind energy voltage and the controller indicates the signal S9V as HIGH (1). The S9V signal indicates that the solar photovoltaic is producing output voltage between $6-9$ Volts.

Referring to Fig. 9 at time $=6$ seconds, wind energy voltage decreased to 5.85 Volts, which is equivalent to digital voltage of 856 and solar photovoltaic voltage increased to 12 Volts. During this time, referring to Fig. 9, Stateflow/Simulink MATLAB controller performs self-intervention from the wind energy to solar photovoltaic source.

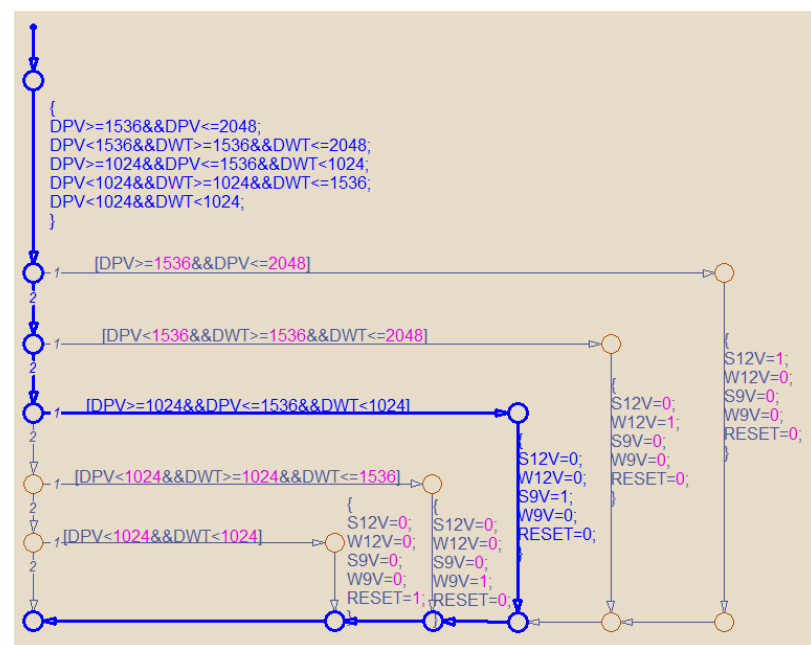

Fig. 8. Solar photovoltaic voltage is between 6 - 9 volts, wind energy voltage is less than 6 volts.

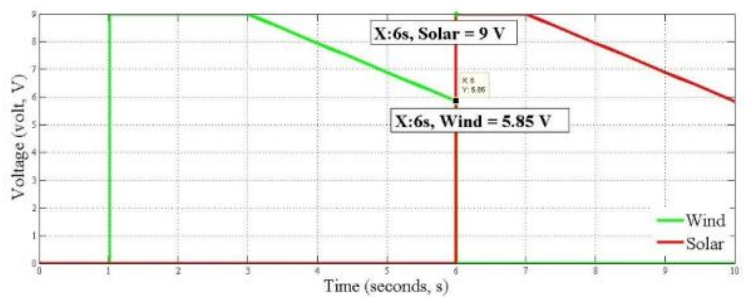

Fig. 9. Self-Intervention wind energy to solar photovoltaic based on condition 3 .

In the following section, one condition from Table II is discussed and explained. The second condition is from Table II when the output voltages from both hybrid renewable energy resources is below than 6 Volts.

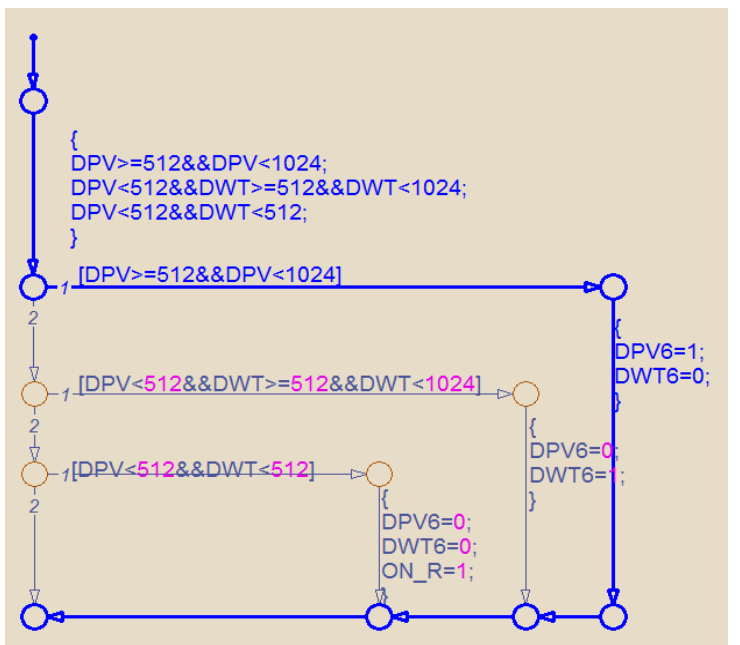

Fig. 10. Solar photovoltaic voltage is between $3-6$ volts, wind energy voltage is less than 3 volts.

i. Condition 1: $3 \leq \mathrm{SP}<6, \mathrm{WE}=2$

Fig. 10 is referring to condition 1 in the Table II, when solar photovoltaic is producing voltage between $3-6$ Volts, while wind energy output voltage is less than 3 Volts. During this condition, solar photovoltaic voltage is always higher compare to the wind energy voltage and the controller indicates the signal DPV6 as HIGH (1). The DPV6 signal indicates that the solar photovoltaic is producing 
output voltage between $3-6$ Volts.

Referring to Fig. 11 at time $=6$ seconds, the wind energy voltage decreased to 2 Volts, which is equivalent to digital voltage of 342 and the Solar Photovoltaic voltage increased to 6 Volts. During this time, referring to Fig. 11, the Stateflow/Simulink MATLAB controller perform the self-intervention from the wind energy to solar photovoltaic source.

Fig. 11. Self-Intervention solar photovoltaic to wind energy based on condition 1.

\section{CONCLUSION}

This research introduces the adaptive voltage-divider sensing method and the self-intervention technique to improve the loading and unloading of the input as the hybrid renewable energy resources. This research was modelled and simulated using the Stateflow/Simulink MATLAB software. The Stateflow chart is used to design and develop the self-intervention technique and is composed as a controller. Simulink was used to design and develop the adaptive voltage-divider sensing method. Both of these are combined to perform the proposed self-intervention between the HPVWES and the output results were analyzed. According to the results, the adaptive voltage-divider-sensing effectively perform the voltage sensing at the $R_{1}$ as shown in Fig. 2, while the Stateflow/Simulink Matlab controller efficiently measured the digital voltages to manage the loading and unloading between the hybridized renewable energy resources.

\section{ACKNOWLEDGMENT}

The author(s) wish to acknowledge the support from the Ministry of Higher Education of Malaysia (MOHE), Centre for Telecommunication Research \& Innovation (CeTRI), Faculty of Electronic and Computer Engineering (FKEKK), Universiti Teknikal Malaysia Melaka (UTeM), Hang Tuah Jaya, 76100, Durian Tunggal, Melaka, MalaysiaUniversiti Teknikal Malaysia Melaka (UTeM) and Brunel University London, United Kingdom.

\section{REFERENCES}

1. G. Mishra and R. Mishra, "Control Strategy For Wind Energy And Hybrid Generating Systems Based On The Concept Of Power Electronics," Int. J. Eng. Comput. Sci., vol. 1, no. 3, pp. 114-120, 2012.

2. S. K. Ramoji and B. J. Kumar, "Optimal Economical sizing of a PV-Wind Hybrid Energy System using Genetic Algorithm and Teaching Learning Based Optimization," Int. J. Adv. Reserach Electr. Electron. Instrum. Eng., vol. 3, no. 2, pp. 7352-7367, 2014.

3. A. Derrouazin, N. Mekkakia-Maaza, R. Taleb, M. Nacef, and M. Aillerie, "Low Cost Hybrid Energies Smart Management System Applied for Micro-grids," Energy Procedia, vol. 50, pp. 729-737, 2014.

4. A. H. Fathima and K. Palanisamy, "Optimization in Microgrids with Hybrid Energy Systems - A Review," Renew. Sustain. Energy Rev., vol. 45, pp. 431-446, 2015.

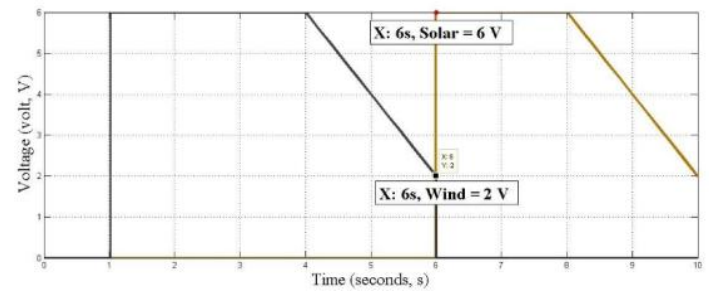

5. N. Chen, X. Qu, W. Weng, and X. Xu, "Design of Wind-solar Complementary Power System Based on Progressive Fuzzy Control," J. Comput., vol. 9, no. 6, pp. 1378-1384, Jun. 2014.

6. R. Belfkira, C. Nichita, P. Reghem, and G. Barakat, "Modeling and Optimal Sizing of Hybrid Renewable Energy System," 2008 13th Int Power Electron. Motion Control Conf., pp. 1834-1839, 2008.

7. E. Koutroulis, D. Kolokotsa, A. Potirakis, and K. Kalaitzakis, "Methodology for Optimal Sizing of Stand-alone Photovoltaic/Wind-Generator Systems using Genetic Algorithms," Sol. Energy, vol. 80, no. 9, pp. 1072-1088, 2006.

8. E. S. Sreeraj, K. Chatterjee, and S. Bandyopadhyay, "Design of Isolated Renewable Hybrid Power Systems," Sol. Energy, vol. 84, no. 7, pp. 1124-1136, 2010.

9. Y.-C. Kuo, Y.-M. Huang, and L.-J. Liu, "Integrated Circuit and System Design for Renewable Energy Inverters," Int. J. Electr. Power Energy Syst., vol. 64, pp. 50-57, 2015.

10. M. F. Almi, M. Arrouf, H. Belmili, S. Boulouma, and B. Bendib, "Energy Management of Wind/PV and Battery Hybrid System," Int. J. New Comput. Arch. their Appl., vol. 4, no. 1, pp. 30-38, 2014.

11. M. Ding, B. Wang, Z. Chen, Z. Chen, Y. Luo, and G. Zheng, "Stabilizing Control Strategy of Complementary Energy Storage in Renewable Energy System," IEEE PES Innov. Smart Grid Technol., pp. 1-5, 2012.

12. C. Wen, Z. Huo, and Z. Li, "Research on PV and Battery Control System with Energy Management Technology in Stand-Alone DC Micro Grid,' in International Industrial Informatics and Computer Engineering COnference (IIICEC 2015), 2015, pp. 331-335.

13. E. M. Natsheh and A. Albarbar, "Hybrid Power Systems Energy Controller Based on Neural Network and Fuzzy Logic," Smart Grid Renew. Energy, vol. 4, no. 2, pp. 187-197, 2013.

14. I. Kougias, S. Szabo, F. Monforti-Ferrario, T. Huld, and K. Bodis, "A Methodology for Optimization of the Complementarity Between Small-Hydropower Plants and Solar PV Systems," Renew. Energy, vol. 87, pp. 1023-1030, 2016.

15. C. de Oliveira Costa Souza Rosa, K. A. Costa, E. da Silva Christo, and P. B. Bertahone, "Complementarity of Hydro, Photovoltaic, and Wind Power in Rio de Janeiro State,” Sustain., vol. 9, no. 7, pp. 1-12, 2017.

16. Y. Li, V. G. Agelidis, and Y. Shrivastava, "Wind-Solar Resource Complementarity and its Combined Correlation with Electricity Load Demand," 2009 4th IEEE Conf. Ind. Electron. Appl. ICIEA 2009, pp. 3623-3628, 2009.

\section{AUTHORS PROFILE}

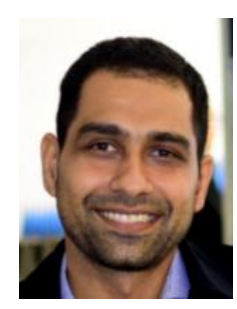

Ir. Dr. Ranjit Singh Sarban Singh is currently attached to Faculty of Electronic and Computer Engineering, Universiti Teknikal Malaysia Melaka as Senior Lecturer. He also is a member of Advanced Sensors \& Embedded Control System Research Group under Center of Telecommunication, Research \& Innovation (CeTRI), Universiti Teknikal Malatsia Melaka. Ir. Dr. Ranjit obtained his Bachelor of Electronic Engineering (Computer Engineering) from Kolej Universiti Teknikal Kebangsaan Malaysia (KUTKM) in 2006, then pursued his Master of Science Engineering by research at Multimedia University, Melaka Malaysia and graduate in 2010. Later in 2013, Ir. Dr. Ranjit was offered scholarship by the Ministry of Higher Education of Malaysia to pursue his PhD in Electronic and Computer Engineering at Brunel University, London, United Kingdom. Ir. Dr. Ranjit graduated in 2016. His research work is focusing on simulation, modelling and development of renewable energy system and embedded system design, development and validation. Ir. Dr. Ranjit also have various numbers of conference and journal papers publication. He is also active in consultation job, such as assisting Engineers from the SDIEM manufacturing company to complete their one-off project. He is also involved in few University-Industry based projects, which are funded by the University and Industry. Also, he is a registered Professional Engineer with the Board of Engineers, Malaysia and involves with Universities accreditation process. Ir. Dr. Ranjit also is registered as Chartered Engineer with The Institution of Engineering and Technology, United Kingdom. Apart from that, he is also appointed as Industrial Advisor by the Politeknik Merlimau Melaka, Malaysia.

\section{Published By:}

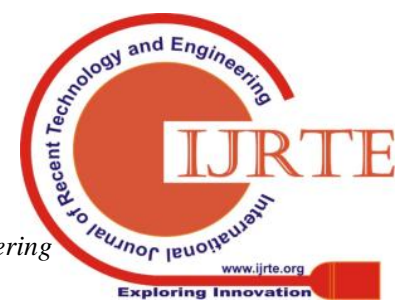




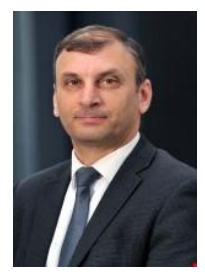

Dr Maysam F. Abbod received BSc degree in Electrical Engineering from University of Technology in 1987. PhD in Control Engineering from University of Sheffield in 1992. From 1993 to 2006 he was with the Department of Automatic Control and Systems Engineering at the University of Sheffield as a research associate and senior research fellow. Dr. Maysam has involved in many consultancy research from year 1996 - 2001 and currently is serving at Department of Electronic and Computer Engineering, College of Engineering, Design and Physical Science of Brunel University London.

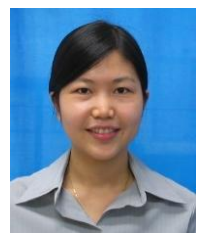

Dr Wong Yan Chiew is the Head of Micro and Nano Electronics (MiNE) research group, Universiti Teknikal Malaysia Melaka (UTeM), Durian Tunggal, Melaka. She is also an Associate Professor at Faculty of Electronics and Computer Engineering, UTeM and teaching integrated circuit design, artificial intelligence, microprocessor and computer engineering subjects. She obtained her B.Eng. and MEng (Master degree) in Universiti Teknologi Malaysia in 2005 and 2008. In 2014, she completed her PhD in Electronics Engineering, School of Engineering, The University of Edinburgh, United Kingdom. Her research work focuses on analog and mixed signal CMOS circuit design, power management system, miniature energy harvester, adaptive/artificial algorithm, reconfigurable RF circuitry and CMOS high voltage controller. Dr Wong has various scientific publications available. Most of the work is in the electronics design, wireless communication field and artificial intelligence. Her recent work focuses on the technology enhanced smart environment. She has also involved in few consultation projects. Dr. Wong participates in multiple international projects such as ARMOURS European project, Adaptive Impedance Module (AIM) SMART project and SWARM Horizon 2020 project. Locally, she involves in Demand-Driven Development (3D) project to build intellectual property (IP) for system-on-chip. She has received more than 20 awards from international or local such as ITEX, INNOVATE, IEM, EDS societies and etc. She has been able to successfully design and develop low power controller, high voltage CMOS control chips and RF circuitries. She is equipped with both design and implementation skills. 